\title{
Avaliação de novos depósitos de argilas do Estado da Paraíba visando sua aplicação como matérias-primas cerâmicas
}

\section{(Assessment of new clay deposits of Paraiba State for application as ceramic raw materials)}

\author{
I. P. Brito, E. P. Almeida, G. A. Neves, R. R. Menezes, V. J. Silva, L. N. L. Santana \\ Unidade Acadêmica de Engenharia dos Materiais, Universidade Federal de Campina Grande, \\ Av. Aprigio Veloso 882, Campina Grande, PB, Brasil 58109-970 \\ igor_pbrito@hotmail.com.br,ester@dema.ufcg.edu.br,gelmires.neves@ufcg.edu.br, \\ Romualdo.menezes@ufcg.edu.br,valmir_jspb@yahoo.com.br,Lisiane.navarro@ufcg.edu.br
}

\begin{abstract}
Resumo
Nos últimos anos novos depósitos de argilas foram descobertos no Estado da Paraíba e a caracterização desses depósitos é de fundamental importância para estabelecer o seu melhor uso industrial. O presente trabalho teve como objetivo caracterizar argilas provenientes de jazidas do município de Cubati, PB, visando estabelecer seus usos adequados como matérias-primas cerâmicas. Para tanto, as matérias-primas foram submetidas às caracterizações física, química, mineralógica e térmica. Posteriormente, foram preparados corpos de prova por prensagem uniaxial a $19 \mathrm{MPa}$, secos em estufa a $110{ }^{\circ} \mathrm{C}$, e submetidos a queima a $750,850,950 \mathrm{e}$ $1150{ }^{\circ} \mathrm{C}$. Foram determinadas as propriedades físico-mecânicas: retração linear de queima, absorção de água, densidade aparente e módulo de ruptura à flexão. Os resultados comprovaram que $\mathrm{SiO}_{2}, \mathrm{Al}_{2} \mathrm{O}_{3}$ e $\mathrm{Fe}_{2} \mathrm{O}_{3}$ foram os principais óxidos presentes nas argilas e que estas são constituídas por esmectita, quartzo e caulinita. A argila contendo maior razão $\mathrm{Al}_{2} \mathrm{O}_{3} / \mathrm{SiO}_{2}$, distribuição granulométrica mais larga e menor diâmetro médio de partícula foi a que apresentou o melhor desempenho mecânico. Três das argilas são adequadas para uso em cerâmica branca e uma para cerâmica vermelha.

Palavras-chave: argilas, caracterização, propriedades.
\end{abstract}

Abstract

In recent years, new clay deposits have been discovered in the state of Paraiba, Brazil, the characterization of these deposits having fundamental importance to establish the best industrial application. The aim of this study was to characterize clays from Cubati, PB, Brazil, to establish their appropriate uses as ceramic raw materials. Therefore, the raw materials were subjected to physical, chemical, mineralogical and thermal characterizations. The specimens were prepared by uniaxial pressing at $19 \mathrm{MPa}$, dryng at $110^{\circ} \mathrm{C}$, and fired at 750,850, 950 and $1150^{\circ} \mathrm{C}$. The following physical and mechanical properties were studied: firing linear shrinkage, water absorption, apparent density and flexural modulus of rupture. The results showed that $\mathrm{SiO}_{2}$, $\mathrm{Al}_{2} \mathrm{O}_{3}$ and $\mathrm{Fe}_{2} \mathrm{O}_{3}$ were the main oxides present in the clays, whicht are constituted by smectite, kaolinite and quartz. The clay containing higher $\mathrm{Al}_{2} \mathrm{O}_{3} \mathrm{SiO}_{2}$ ratio, wider size distribution and the lower average particle diameter was the one that presented best mechanical performance. Three clays are suitable for use in white ceramic and one to red ceramic.

Keywords: clays, characterization, properties

\section{INTRODUÇÃO}

Os materiais cerâmicos têm uma grande gama de aplicações, pois é usado desde o adobe, tipo de tijolo cru, até prótese dentária, isolante elétrico e revestimento de reatores nucleares. Entretanto, o uso mais visível dos materiais cerâmicos é na indústria da construção civil.

A principal matéria-prima da indústria cerâmica é a argila, que é definida como um material natural, terroso, de granulação fina que quando umedecido com água apresenta plasticidade; quimicamente, são materiais formados essencialmente por silicatos hidratados de alumínio, ferro e magnésio, denominados argilominerais [1]. Por ser composta de combinações de diversos minerais, a argila pode ser classificada conforme a sua origem, composição química e concentração dos argilominerais. Foi reportado que existem cerca de quarenta variedades de argilominerais e as mais utilizadas nas indústrias cerâmicas são as cauliníticas, ilíticas, montmoriloníticas sendo acompanhada de minerais acessórios, tais como: sílica, mica, carbonatos, sulfatos e hematita [2]. As argilas naturais são relativamente abundantes; portanto, novas jazidas têm sido descobertas em várias partes do Brasil e, em particular, no estado da Paraíba. Além disso, apresentam baixo custo, que associado ao seu grande potencial de uso, atrai a atenção da indústria e da comunidade científica. Por outro lado, para uma utilização eficiente das argilas, principalmente dos novos depósitos, é salutar a realização de um controle de qualidade, que, em 
geral, é dificultado pelas variações mineralógicas das argilas e grau de alteração que as rochas apresentam. Esta situação pode gerar problemas, como menor produção, geração de rejeitos, extração inadequada da matéria-prima e danos ao meio ambiente. Para minimizar estes efeitos indesejáveis é necessário conhecimento das características das matériasprimas e suas combinações [3]. No entanto, nos últimos anos tem crescido o interesse pelo conhecimento mais aprofundado das características das argilas [4-7].

O objetivo do presente trabalho é a caracterização dos materiais argilosos, por meio das técnicas de análises química, térmica, mineralógica e granulométrica dos novos depósitos de argilas do estado da Paraíba, visando seu uso como matérias-primas cerâmicas.

\section{MATERIAIS E MÉTODOS}

Foram utilizadas quatro argilas provenientes do município de Cubati, PB. As argilas denominadas A, B, C e $D$ foram secas em estufa a $110^{\circ} \mathrm{C}$, em seguida submetidas ao processo de britagem, em um britador de mandíbula, para proporcionar redução no tamanho dos aglomerados. Posteriormente, foram submetidas à moagem em moinhos de martelo e galga com objetivo de transformá-las em pó. Após moagem as argilas foram passadas em peneira ABNT $200(0,074 \mathrm{~mm})$ para os ensaios de caracterização, e em peneira ABNT $80(0,018 \mathrm{~mm})$ para os ensaios tecnológicos.

A caracterização das amostras das argilas foi efetuada por meio das seguintes técnicas: análise granulométrica por espalhamento laser (Cilas $1064 \mathrm{~L} / \mathrm{D})$, análise química por fluorescência de raios X (Shimadzu EDX 720), análise termogravimétrica (TG) e análise térmica diferencial (ATD) (sistema de análise térmica simultânea Shimadzu TA 60H), com taxa de aquecimento $12,5^{\circ} \mathrm{C} / \mathrm{min}$ sob atmosfera de ar (temperatura máxima $1000{ }^{\circ} \mathrm{C}$ e padrão na ATD o óxido de alumínio calcinado), difração de raios X (Shimadzu D6000) com radiação Cuk $\alpha(40 \mathrm{kV} / 30 \mathrm{~mA})$ e velocidade do goniômetro de $2 \%$ min e passo $0,02^{\circ}$, na faixa de 5 a $60^{\circ}$.

Para conformação das massas, foi adicionado um teor de umidade de 7,0\% do peso total da argila, e a massa foi homogeneizada no moinho de bolas por $24 \mathrm{~h}$ e armazenada por mais $24 \mathrm{~h}$. Depois do repouso, as massas foram conformadas por prensagem uniaxial (Servitech CT-335), os corpos de prova retangulares foram obtidos aplicando-se $19 \mathrm{MPa}$. Após a etapa de conformação, os corpos de prova foram secos em estufa a $110^{\circ} \mathrm{C} / 24 \mathrm{~h}$, e sinterizados em forno (Flyever FE $50 \mathrm{RP}$ ) a $750,850,950$ e $1150{ }^{\circ} \mathrm{C}$ com taxa de aquecimento $2{ }^{\circ} \mathrm{C} / \mathrm{min}$, patamar de $2 \mathrm{~h}$ na temperatura máxima de queima. Após o processo de sinterização, os corpos de prova foram submetidos a ensaios tecnológicos para determinação das propriedades físico-mecânicas de retração linear de queima (RLq), absorção de água (AA), densidade aparente (DAp) e módulo de ruptura à flexão (MRF).

\section{RESULTADOS E DISCUSSÃO}

A Tabela I mostra a composição química das amostras analisadas. A fração de sílica (dióxido de silício - $\mathrm{SiO}_{2}$ ) variou de $41,20 \%$ para a argila $\mathrm{C}$ a $47,12 \%$ para a argila $\mathrm{B}$. Com relação ao teor de alumina $\left(\mathrm{Al}_{2} \mathrm{O}_{3}\right)$, os valores variaram de $19,49 \%$ para a argila D a $28,63 \%$ para a argila B. Para o óxido de ferro $\left(\mathrm{Fe}_{2} \mathrm{O}_{3}\right)$ nota-se que a argila $\mathrm{D}$ apresentou o maior teor, 9,97\%, e a argila A o menor, 3,60\%. Em trabalho que tinha como objetivo analisar a influência de diferentes tratamentos térmicos sobre as mudanças mineralógicas e microestruturais de argilas [8], foi observado que os óxidos mais abundantes em todas as argilas foram: $\mathrm{SiO}_{2}$ variando de 49,99 a 57,86\%, $\mathrm{Al}_{2} \mathrm{O}_{3}$ de 22,42 a 27,49\%; e de $\mathrm{Fe}_{2} \mathrm{O}_{3}$ de 3,82 a $4,66 \%$. Esta tendência também foi observada para as argilas analisadas neste trabalho. Os teores de $\mathrm{SiO}_{2}$ estão associados à presença de argilominerais e quartzo, enquanto os de $\mathrm{Al}_{2} \mathrm{O}_{3}$ estão relacionados à caulinita. A razão das frações de alumina e sílica $\left(\mathrm{Al}_{2} \mathrm{O}_{3} / \mathrm{SiO}_{2}\right)$ variou de 0,44 para a argila $\mathrm{D}$ e 0,62 para a argila $\mathrm{C}$, cujos resultados estão de acordo com os obtidos em outros trabalhos $[9,10]$. Na Tabela I ainda pode ser observado que as frações de $\mathrm{Fe}_{2} \mathrm{O}_{3}$, $\mathrm{MgO}$ e $\mathrm{K}_{2} \mathrm{O}$ da argila $\mathrm{D}$ são superiores às das demais argilas, podendo estar presentes em materiais que irão agir como fundentes durante a etapa de queima.

Com relação à perda de massa, verifica-se que variou de $16,87 \%$ para argila B e $21,72 \%$ para a argila C; estas perdas possivelmente estão relacionadas com a evaporação de águas coordenadas e adsorvidas, hidroxilas dos argilominerais e queima da matéria orgânica.

A Tabela II mostra a distribuição granulométrica das quatro amostras de argilas: A, B, C e D. A argila A é

Tabela I - Composições químicas (\%) das argilas.

[Table I - Chemical compositions (\%) of the clays.]

\begin{tabular}{cccccccccc}
\hline Amostras & $\mathrm{PF}^{*}$ & $\mathrm{SiO}_{2}$ & $\mathrm{Al}_{2} \mathrm{O}_{3}$ & $\mathrm{Fe}_{2} \mathrm{O}_{3}$ & $\mathrm{MgO}$ & $\mathrm{TiO}_{2}$ & $\mathrm{CaO}$ & $\mathrm{K}_{2} \mathrm{O}$ & $\begin{array}{c}\text { Outros } \\
\text { óxidos }\end{array}$ \\
\hline Argila A & 19,01 & 46,73 & 26,61 & 3,60 & 1,54 & 1,23 & 0,41 & 0,63 & 0,21 \\
Argila B & 16,87 & 47,12 & 28,63 & 3,97 & 1,24 & 1,15 & 0,45 & 0,46 & 0,08 \\
Argila C & 21,72 & 41,20 & 25,67 & 5,67 & 2,16 & 1,01 & 0,71 & 0,42 & 1,41 \\
Argila D & 20,31 & 44,05 & 19,49 & 9,97 & 2,72 & 0,69 & 0,40 & 1,84 & 0,49 \\
\hline
\end{tabular}

*PF: Perda ao fogo. 
composta de $29,5 \%$ de argila e $70,5 \%$ de silte, com diâmetro médio de $4,16 \mu \mathrm{m}$; a argila B apresenta fração volumétrica de $50,18 \%$ de argila e $49,82 \%$ de silte, diâmetro médio de $3,17 \mu \mathrm{m}$; a argila C contém $63,16 \%$ de argila e $36,84 \%$ de silte, diâmetro médio de $2,30 \mu \mathrm{m}$. Já a argila $\mathrm{D}$ é composta de $32,90 \%$ de argila, $66,59 \%$ de silte e $0,51 \%$ de areia, diâmetro médio de $4,27 \mu \mathrm{m}$.

As curvas de distribuição granulométrica das amostras das $\operatorname{argilas~A,~B,~C~e~D~estão~apresentadas~na~Fig.~1.~As~}$ curvas dos histogramas de frequência das amostras das argilas C e D são bimodais, da argila A é unimodal e da argila B é multimodal. Para a argila A (Fig. 1a), 29,5\% das partículas tem diâmetro inferior a $2,0 \mu \mathrm{m}$, a maior concentração de partícula encontra-se entre $1,6 \mu \mathrm{m}$ e $6,0 \mu \mathrm{m}$ e as maiores partículas, representando $0,21 \%$, apresentaram diâmetro entre 16 e $18 \mu \mathrm{m}$. Para a argila B (Fig. 1b), 50,18\% das partículas tem diâmetro inferior a $2,0 \mu \mathrm{m}$, a maior concentração de partículas encontra-se com diâmetro entre 0,3 e 3,0 $\mu \mathrm{m}$ e as maiores partículas com diâmetro entre 13 e $15 \mu \mathrm{m}$, representa apenas $0,36 \%$ do total. Para a argila C (Fig. 1c) 63,16\% das partículas tem diâmetro inferior a 2,0 $\mu \mathrm{m}$, sendo que a maior concentração de partículas encontra-se entre 0,6 e 3,6 $\mu \mathrm{m}$ e as maiores partículas tem diâmetro de 13 a $15 \mu \mathrm{m}$ e representam $\sim 0,58 \%$ da amostra. Para a argila D (Fig. 1d), a fração volumétrica com diâmetro inferior a $2,0 \mu \mathrm{m}$ representou $32,9 \%$ da amostra, mais de

Tabela II - Composição granulométrica das argilas.

[Table II - Granulometric composition of the clays.]

\begin{tabular}{ccccc}
\hline Amostra & $\begin{array}{c}\text { Argila (\%) } \\
(\mathrm{x} \leq 2 \mu \mathrm{m})\end{array}$ & $\begin{array}{c}\text { Silte }(\%) \\
(2 \mu \mathrm{m}<\mathrm{x} \leq 20 \mu \mathrm{m})\end{array}$ & $\begin{array}{c}\text { Areia (\%) } \\
(\mathrm{x}>20 \mu \mathrm{m})\end{array}$ & $\begin{array}{c}\text { Diâmetro médio } \\
(\mu \mathrm{m})\end{array}$ \\
\hline Argila A & 29,50 & 70,50 & 0,0 & 4,16 \\
Argila B & 50,18 & 49,82 & 0,0 & 3,17 \\
Argila C & 63,16 & 36,84 & 0,0 & 2,30 \\
Argila D & 32,90 & 66,59 & 0,51 & 4,27 \\
\hline
\end{tabular}
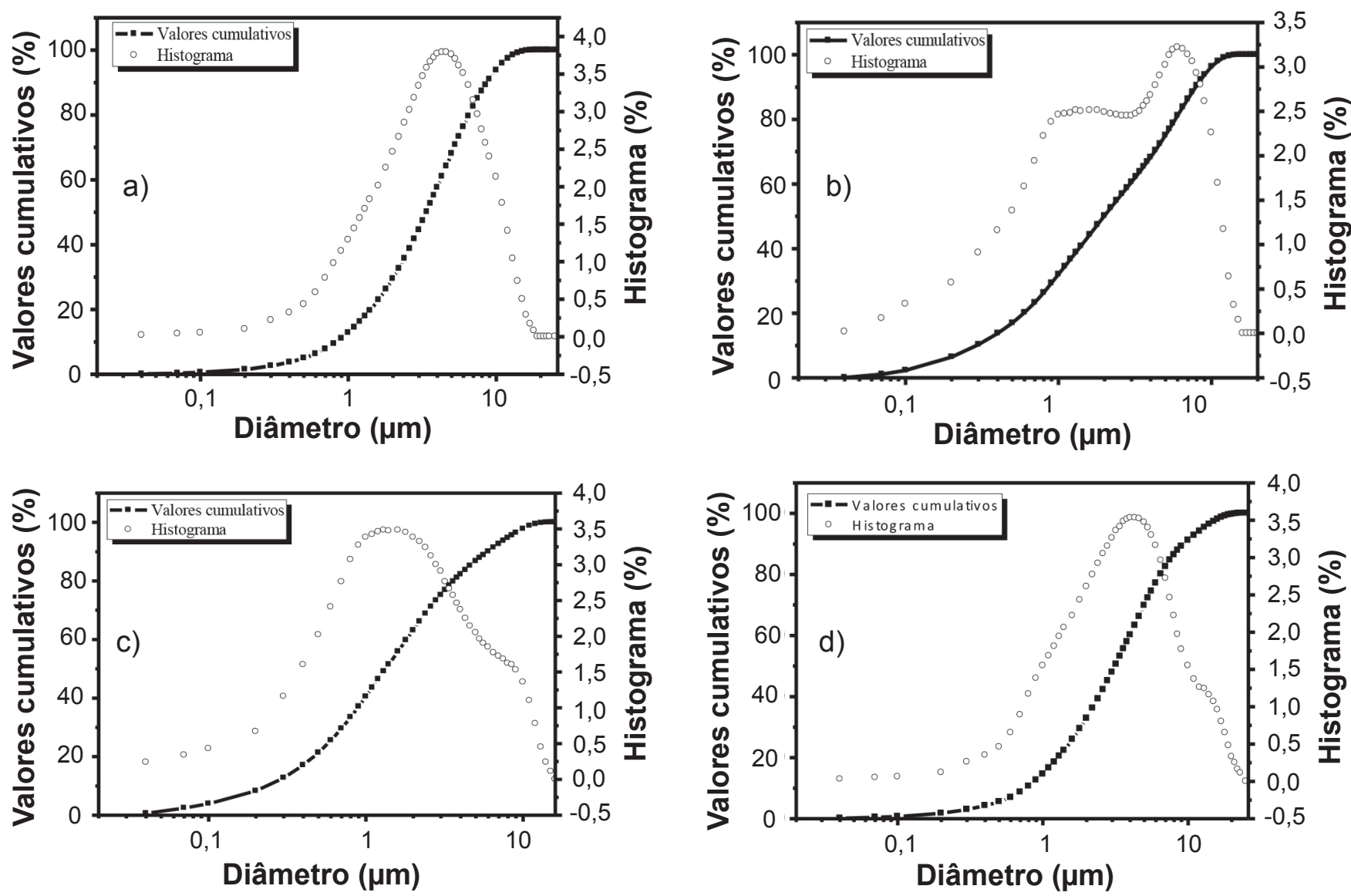

Figura 1: Distribuição do diâmetro equivalente das partículas: (a) argila A; (b) argila B; (c) argila C e (d) argila D.

[Figure 1: Distribution of the equivalent diameter of the particles: (a) clay A; (b) clay B; (c) clay C and (d) clay D.] 
$50 \%$ da amostra apresentaram partículas com diâmetro entre 1,6 e $6 \mu \mathrm{m}$, sendo as maiores concentrações na faixa de 3,4 e 5,3 $\mu \mathrm{m}$ e as partículas com os maiores diâmetros entre 20 e $23 \mu \mathrm{m}$ representam apenas $0,51 \%$ de todas as partículas.

Argilas oriundas da jazida da Fazenda Campos Novos, Cubati, PB, foram analisadas [11], sendo obtida concentração de partículas em torno de 3 a $4 \mu \mathrm{m}$, de $15 \mu \mathrm{m}$ e de 25 a $30 \mu \mathrm{m}$, tamanhos médios de partículas variando de 3,8 a $8,1 \mu \mathrm{m}$ e fração volumétrica com diâmetro abaixo de $2 \mu \mathrm{m}$ variando de $20,41 \%$ (amostra 6) a 41,36\% (amostra 1), ou seja, tamanhos médios de partículas semelhantes aos obtidos neste trabalho para as argilas A e D.

Ressalta-se que uma determinada argila, oriunda do município de Boa Vista, PB, é utilizada em uma série de aplicações comerciais e apresenta um diâmetro médio de 2,6 $\mu \mathrm{m}$ e uma fração volumétrica média inferior a $2 \mu \mathrm{m}$ de $46 \%$ [11]. Portanto, observa-se que as argilas B e C apresentam concentração de partícula com fração volumétrica com diâmetro menor que 2,0 $\mu \mathrm{m}$ superiores a argila descrita, com destaque para a argila $\mathrm{C}(63,16 \%)$ que também apresentou um diâmetro médio das partículas inferior ao da mesma. Quatro amostras de argilas oriundas do município de Pedra Lavrada, PB, foram analisadas [12] e encontrado diâmetro médio das partículas variando entre 3,29 e $12,25 \mu \mathrm{m}$. Com relação à fração volumétrica com diâmetro inferior a $2 \mu \mathrm{m}$, foram obtidos valores variando entre 47,23 e 9,26\%.

A Fig. 2 apresenta os difratogramas de raios $\mathrm{X}$ das amostras estudadas. Pode-se observar a presença dos seguintes argilominerais: esmectita (JCPDS 13-0135) e caulinita (JCPDS 79-1570), e dos minerais, quartzo (JCPDS 46-1045) e feldspato (JCPDS 89-8575).

$\mathrm{O} \mathrm{Fe}_{2} \mathrm{O}_{3}$ presente nas amostras está possivelmente associado ao ferro presente na estrutura cristalina do argilomineral do grupo da esmectita, uma vez que não foram observadas as presenças de goetita, ilita ou outras fases, que poderiam ser fontes de óxidos e hidróxidos de ferro.

A Fig. 3 apresenta as curvas das análises térmicas

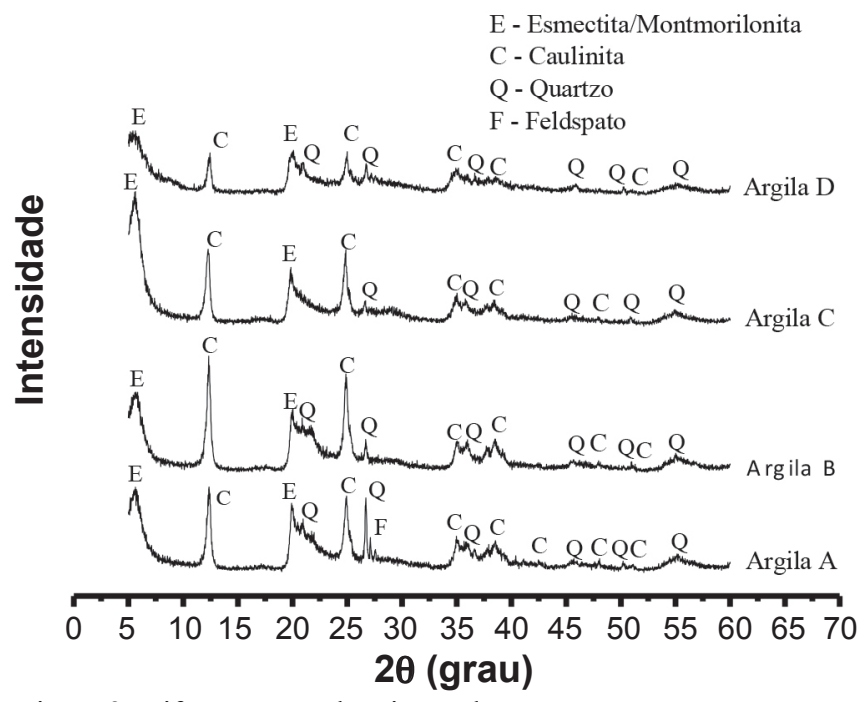

Figura 2: Difratogramas de raios $\mathrm{X}$ das amostras.

[Figure 2: XRD patterns of the samples.] diferenciais ( $\Delta \mathrm{T}$ - diferença de temperatura) e térmicas gravimétricas (PM - perda de massa). Nas curvas $\Delta \mathrm{T}$ observase um pico endotérmico mais intensos em $84,8^{\circ} \mathrm{C}$ para a argila $\mathrm{A}, 78,6{ }^{\circ} \mathrm{C}$ para a argila $\mathrm{B}, 97^{\circ} \mathrm{C}$ para a argila $\mathrm{C}$ e $93,8{ }^{\circ} \mathrm{C}$ para a argila $\mathrm{D}$. A existência deste pico provavelmente está associada à evaporação de água livre e adsorvida, uma vez que a evaporação é um processo endotérmico. Por outro lado, observam-se pequenos picos exotérmicos próximo de $200{ }^{\circ} \mathrm{C}$, provavelmente decorrentes da queima de matérias orgânicas. Outro pico endotérmico é observado entre 500 e $520{ }^{\circ} \mathrm{C}$ nas quatro amostras, possivelmente decorrente da desidroxilação dos argilominerais. Picos exotérmicos em todas as amostras são observados entre 915 e $955{ }^{\circ} \mathrm{C}$, que podem estar relacionados com o rearranjo estrutural e com a nucleação de mulita, uma vez que ambas as amostras apresentaram caulinita e esmectita em sua composição, Fig. 2. Em análise das características químicas e físicas de argilas da Tunísia foram observadas reações endotérmicas e exotérmica dentro das mesmas faixas observadas neste trabalho, justificando que a baixa temperatura de desidroxilação pode ser um resultado da fraca cristalinidade de caulinita [13].

A Tabela III apresenta as cores dos corpos de prova após queima a $750,850,950$ e $1150{ }^{\circ} \mathrm{C}$ e o seu uso provável.

Baseado nas cores das argilas industriais brasileiras tomadas como referência [1], as argilas A, B e C têm uso provável em cerâmica branca e fabricação de material refratário sílico-aluminoso; a argila $\mathrm{D}$ terá uso provável em cerâmica vermelha ou estrutural. As amostras A e B queimam com cor creme nas temperaturas a 750,850 e $950^{\circ} \mathrm{C}$ e com cor amarela clara a $1150{ }^{\circ} \mathrm{C}$; a amostra $\mathrm{C}$ queima com cor marrom na temperatura de $750{ }^{\circ} \mathrm{C}$, com cor creme nas temperaturas de 850 e $950{ }^{\circ} \mathrm{C}$, e com cor laranja avermelhado na temperatura de $1150^{\circ} \mathrm{C}$. E a amostra $\mathrm{D}$ que foi a única que apresentou característica de argila para cerâmica vermelha, apresentando cores: marrom avermelhado após queima a $750{ }^{\circ} \mathrm{C}$, laranja a 850 e $950{ }^{\circ} \mathrm{C}$ e vermelha a $1150{ }^{\circ} \mathrm{C}$.

As Figs. 4 a 7 mostram os resultados dos ensaios físico-mecânicos das argilas após queima a 750, 850, 950 e $1150^{\circ} \mathrm{C}$. A Fig. 4 apresenta os valores obtidos para retração linear após a queima das argilas A, B, C e Da 750, 850,950 e $1150{ }^{\circ} \mathrm{C}$.

A retração linear aumenta com o aumento da temperatura de queima para as argilas estudadas. Este comportamento estaria relacionado ao maior grau de sinterização e densificação, provocado por mudanças físicas e redução do volume dos corpos de prova. De uma forma geral, a argila D foi a que apresentou maior retração, podendo esse resultado estar relacionado com o maior teor de óxidos fundentes, que favorece a formação da fase líquida e a maior densificação.

A Fig. 5 apresenta os valores obtidos para absorção de água após a queima das argilas a $750,850,950$ e $1150^{\circ} \mathrm{C}$.

$\mathrm{O}$ teor de absorção de água diminuiu com o aumento da temperatura. A explicação seria o preenchimento dos poros devido a fusão dos óxidos fundentes presente nas massas cerâmicas, o que acarretaria na redução da porosidade. A 

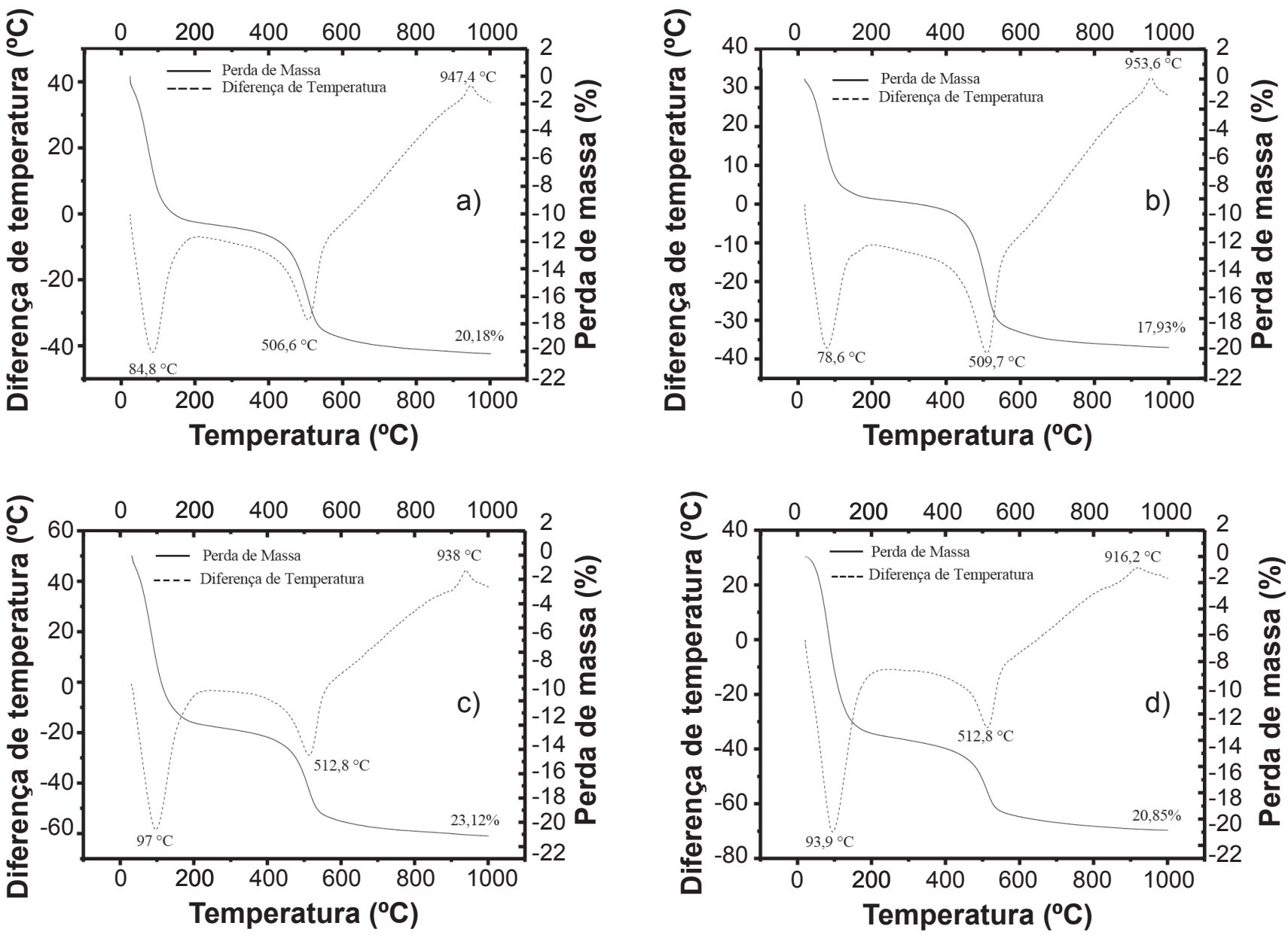

Figura 3: Curvas de ATD/TG das amostras: (a) A; (b) B; (c) C; (d) D. [Figure 3: DTA/TG curves of samples: (a); (b) B; (c) C; (d) D.]

Tabela III - Cores dos corpos de prova após queima a 750, 850, 950 e $1150^{\circ} \mathrm{C}$.

[Table III - Colors of the specimens after firing at 750, 850, 950 and $1150^{\circ} \mathrm{C}$.]

\begin{tabular}{cccccc}
\hline Amostras & $750{ }^{\circ} \mathrm{C}$ & $850{ }^{\circ} \mathrm{C}$ & $950{ }^{\circ} \mathrm{C}$ & $1150{ }^{\circ} \mathrm{C}$ & Uso provável \\
\hline Argila A & Creme & Creme & Creme & Amarelo Claro & $\begin{array}{l}\text { Cerâmica branca e material } \\
\text { refratário sílico-aluminoso } \\
\text { Argila B }\end{array}$ \\
Argila C & $\begin{array}{c}\text { Creme } \\
\text { Marrom }\end{array}$ & Creme & Creme & Amarelo Claro & $\begin{array}{c}\text { Cerâmica branca e material } \\
\text { refratário sílico-aluminoso }\end{array}$ \\
Argila D & $\begin{array}{c}\text { Marrom } \\
\text { avermelhado }\end{array}$ & Laranja & Laranja & $\begin{array}{c}\text { Laranja } \\
\text { avermelhado }\end{array}$ & $\begin{array}{c}\text { Cerâmica branca e material } \\
\text { refratário sílico-aluminoso }\end{array}$ \\
\hline
\end{tabular}

argila B por conter menor quantidade de óxidos fundentes foi entre as argilas estudadas a que apresentou a maior absorção de água. Diferentemente, os corpos de prova da argila D, que possui elevada quantidade de óxidos fundentes, apresentaram menor absorção de água após queima. Comparando os resultados da absorção de água das argilas na temperatura de $950{ }^{\circ} \mathrm{C}$ com os de argilas industriais brasileiras tomadas como referência por Souza Santos [1], verifica-se que as argilas A, B e C encontramse classificadas na faixa de variação da absorção de água para argilas plástico-refratárias, e a argila D para cerâmica vermelha. A argila D por apresentar cor que tende a ficar vermelho após queima é apropriado para fabricação de tijolos furados na temperatura de $750{ }^{\circ} \mathrm{C}$ e para a fabricação 


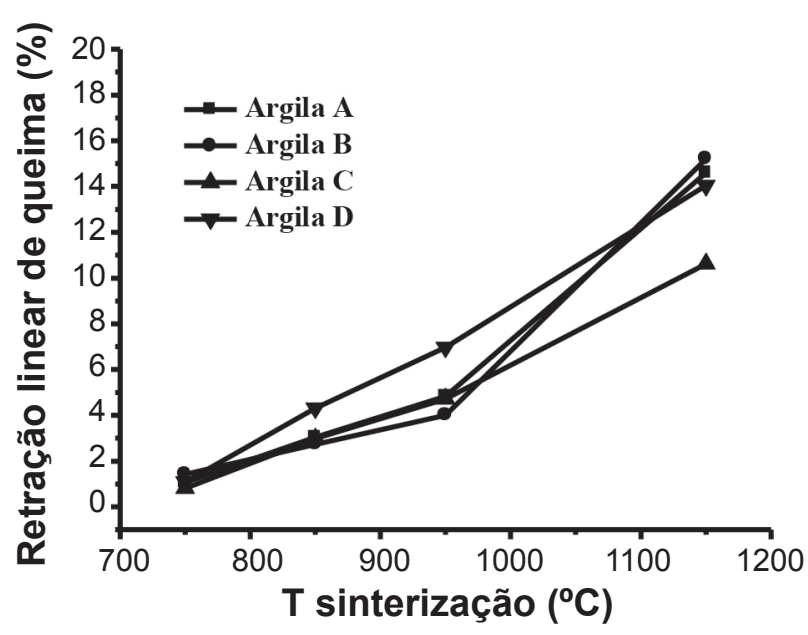

Figura 4: Retração linear de queima dos corpos de prova. [Figure 4: Firing linear shrinkage of the specimens.]

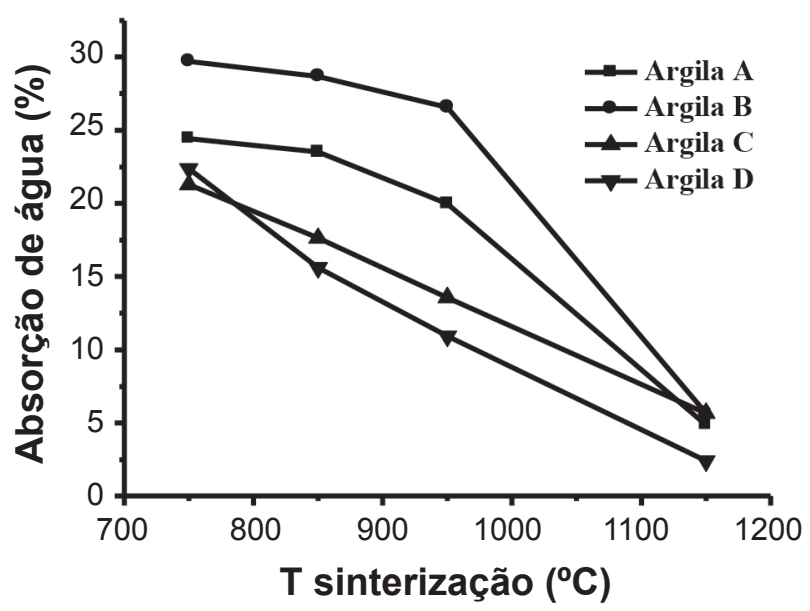

Figura 5: Absorção de água dos corpos de prova após queima. [Figure 5: Water absorption of the specimens after firing.]

de telhas nas temperaturas de 850,950 e $1150{ }^{\circ} \mathrm{C}$ [1].

A Fig. 6 apresenta os valores de densidade aparente para $750,850,950$ e $1150{ }^{\circ} \mathrm{C}$. A densidade aparente aumenta com o aumento da temperatura de queima para todas as argilas, indicando um bom grau de sinterização das partículas que compõem as massas cerâmicas. Isto se dá pela melhor acomodação das partículas devido ao processo de difusão e, também, formação da fase líquida que, durante o processo de sinterização, penetra nos poros existentes, densificando, assim, o material. Os valores obtidos na densidade aparente de todas as argilas, exceto a argila $\mathrm{D}$, na temperatura de $950^{\circ} \mathrm{C}$ encontram-se dentro da faixa para as argilas plástico-refratárias, enquanto que a argila D estar dentro da faixa para cerâmica vermelha [1].

A Fig. 7 apresenta os valores obtidos para módulo de ruptura à flexão após a queima dos corpos de prova obtidos com as massas A, B, C e D a $750,850,950$ e $1150^{\circ} \mathrm{C}$.

De forma geral, o módulo de ruptura cresce com o aumento da temperatura de queima empregada para o processo de sinterização. Pode-se observar que entre 750 a $950{ }^{\circ} \mathrm{C}$ a amostra $\mathrm{C}$ foi a que revelou o melhor desempenho mecânico, comparando com as suas propriedades química e granulométrica, nota-se que esta argila apresentou o menor teor de sílica, a maior relação $\mathrm{Al}_{2} \mathrm{O}_{3} / \mathrm{SiO}_{2}$, uma larga distribuição granulométrica e o menor diâmetro médio de partículas. Esses são os fatores primordiais para a compactação e densificação das partículas, favorecendo as propriedades físico-mecânica. Os resultados do módulo de ruptura à flexão das argilas a $950{ }^{\circ} \mathrm{C}$ ao serem comparados com os de argilas que foram tomadas como referência, indicam que todas as argilas são empregadas para o uso em argilas plástico-refratárias, até mesmo a argila $\mathrm{D}$ [1]. Em $1150{ }^{\circ} \mathrm{C}$ a argila $\mathrm{D}$ apresentou maior módulo de ruptura. Fazendo uma correlação com a composição química da amostra, verificase que esta tem o maior teor de óxidos fundentes, os quais formam fase líquida, preenchendo os poros, que são defeitos volumétricos concentradores de tensões e que podem comprometer as propriedades mecânicas.

A Fig. 8 apresenta difratogramas de raios $\mathrm{X}$ das argilas A, B, C e D após queima nas temperaturas de 750, 850, 950 e $1150{ }^{\circ} \mathrm{C}$.

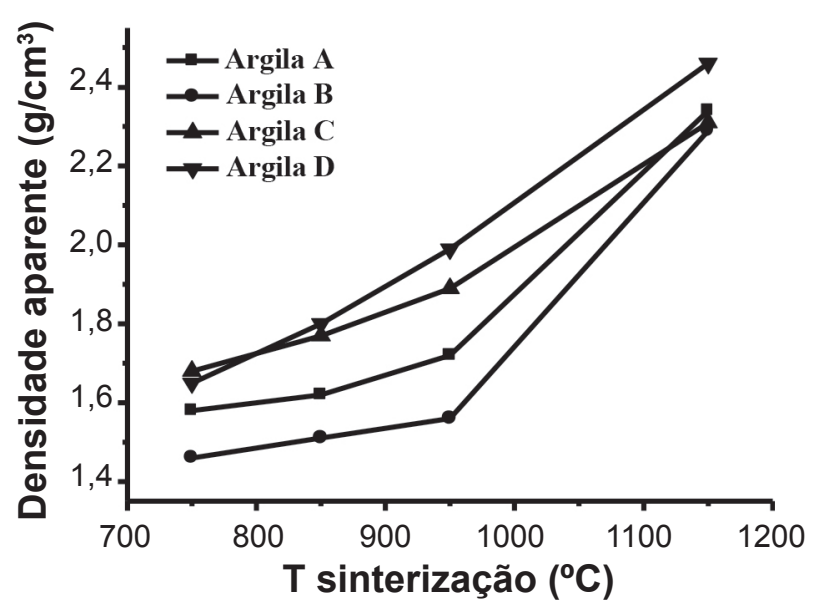

Figura 6: Densidade aparente dos corpos de prova após queima. [Figure 6: Apparent density of the specimens after firing.]

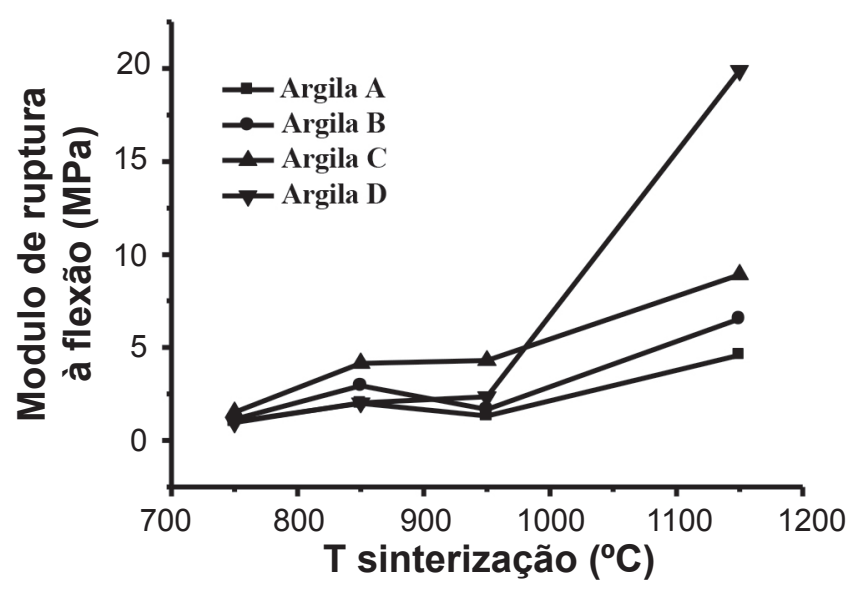

Figura 7: Módulo de ruptura à flexão dos corpos de prova após queima.

[Figure 7: Flexural modulus of rupture of the specimens after firing.] 

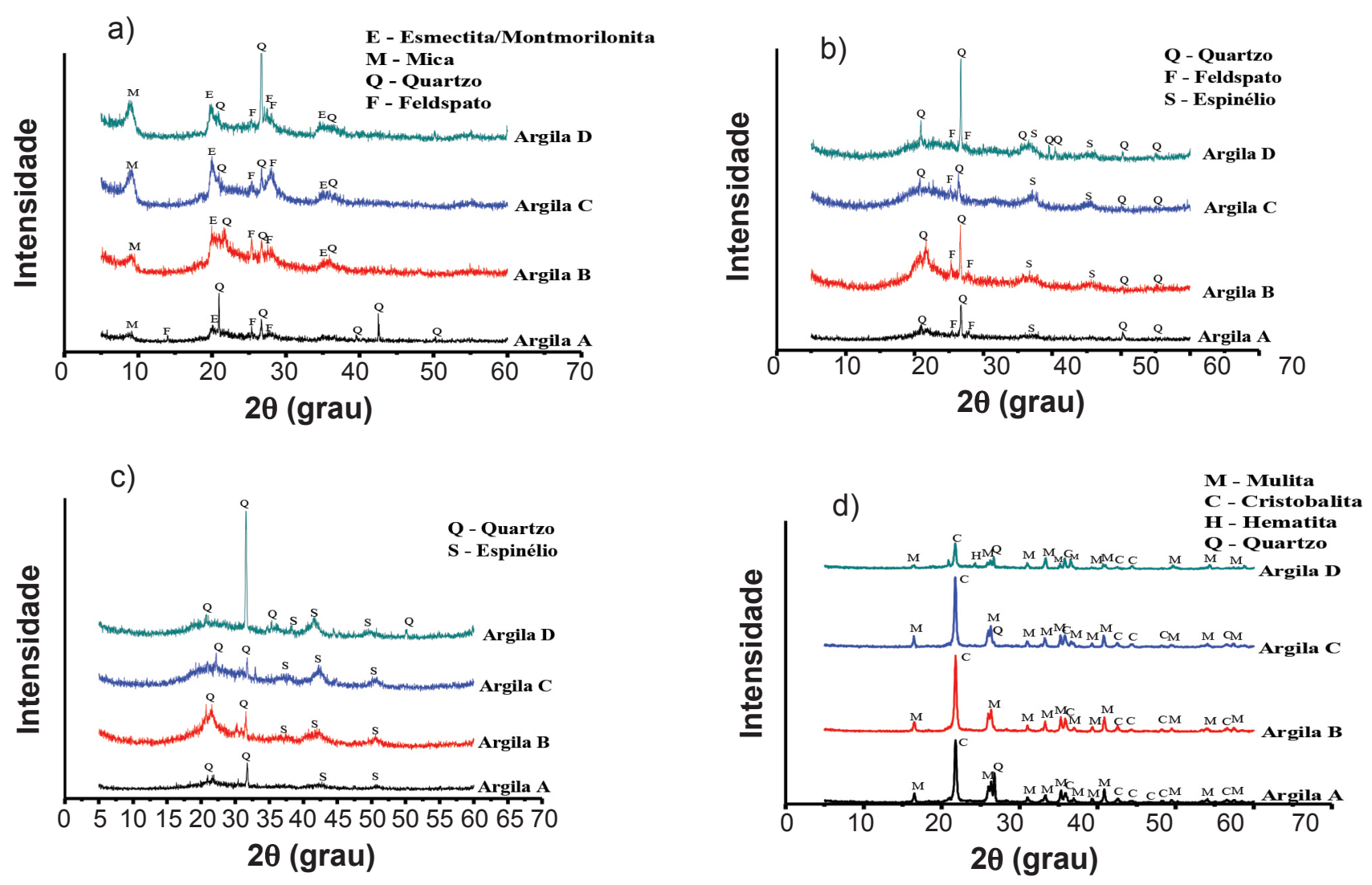

Figura 8: Difratogramas de raios $\mathrm{X}$ das amostras após queima de: (a) $750{ }^{\circ} \mathrm{C}$; (b) $850{ }^{\circ} \mathrm{C}$; (c) $950{ }^{\circ} \mathrm{C}$ e (d) $1150{ }^{\circ} \mathrm{C}$. [Figure 8: XRD patterns of the samples after firing of: (a) $750^{\circ} \mathrm{C}$; (b) $850^{\circ} \mathrm{C}$; (c) $950^{\circ} \mathrm{C}$ and (d) $1150^{\circ} \mathrm{C}$.]

A evolução das fases cristalinas presentes nas argilas A, B, C e D em função da temperatura de queima podem ser resumidas das seguintes maneiras: a $750^{\circ} \mathrm{C}$ as fases cristalinas na amostra são mica (JCPDS 83-1808), esmectita, quartzo e feldspato; a $850^{\circ} \mathrm{C}$ observa-se a presença de quartzo, feldspato e espinélio (JCPDS 87-0340); a $950{ }^{\circ} \mathrm{C}$ apenas o quartzo e o espinélio são detectados; já a $1150{ }^{\circ} \mathrm{C}$ é possível observar picos de mulita (JCPDS 83-1881), cristobalita (JCPDS 820512), hematita (JCPDS 87-1164) e quartzo. Essas mesmas fases foram observadas no estudo da influência de diferentes tratamentos térmicos sobre as transformações de fases esmectitas em temperaturas variando de 800 a $1100{ }^{\circ} \mathrm{C}$ [8]; porém, a presença da fase hematita não foi detectada, fato este atribuído à composição química das argilas que apresentaram teores de $\mathrm{Fe}_{2} \mathrm{O}_{3}$ inferiores aos observados na argila D (Tabela I). Pode-se observar que para a temperatura de $750^{\circ} \mathrm{C}$, picos de esmectita e mica ainda foram detectados; no entanto, observou-se que houve a desidroxilação da estrutura da caulinita, pois não apareceram seus picos característicos. Estes dados estão de acordo com a literatura quando estudos sobre transformações de argilas altamente aluminosas brasileiras durante a queima mostraram que a desidroxilação da caulinita ocorreu entre 450 e $600{ }^{\circ} \mathrm{C}$ [14]. Para as temperaturas de 850 e $950^{\circ} \mathrm{C}$ observa-se uma banda para $2 \theta$ variando de 17 a $23^{\circ}$, sendo esta característica da formação da fase líquida. Para as argilas C e D, que apresentaram maior teor de óxidos fundentes, a intensidade da banda foi maior. E a $1150{ }^{\circ} \mathrm{C}$ foram identificados picos de mulita, de cristobalita e de hematita.

No estudo das transformações de fases de argilas esmectitas submetidas a tratamento térmico entre 800 e $1300{ }^{\circ} \mathrm{C}$, foram identificados picos característicos da esmectita até $800^{\circ} \mathrm{C}$, picos de espinélio entre 900 e $1200{ }^{\circ} \mathrm{C}$, e a cristalização da cristobalita acima da temperatura de $1000{ }^{\circ} \mathrm{C}[15,16]$. A nucleação e crescimento dos cristais de mulita só foram observados a partir da temperatura de $1100{ }^{\circ} \mathrm{C}$. Estes dados corroboram com os estudos reportados $[16,17]$.

\section{CONCLUSÕES}

As amostras são compostas por argilomineral esmectita, caulinita e quartzo. A argila que apresentou a maior razão de $\mathrm{Al}_{2} \mathrm{O}_{3} / \mathrm{SiO}_{2}$, menor teor de sílica, distribuição granulométrica mais larga e o menor diâmetro médio de partícula foi a que proporcionou o melhor desempenho mecânico. As argilas A, B e C são apropriadas para argilas plásticas aplicadas em cerâmica branca do tipo ball-clay e a argila D para utilização em cerâmica vermelha ou estrutural.

\section{AGRADECIMENTOS}

À CAPES pelo auxilio financeiro e aos colegas do Laboratório de Tecnologia de Materiais da Universidade Federal de Campina Grande, pela ajuda no trabalho experimental. 


\section{REFERÊNCIAS}

[1] P. Souza Santos, Ciência e Tecnologia de Argilas, Vol. 1, 2a Ed., Edgar Blücher, S. Paulo, SP (1992) 1; 186-188; 195-196; 397.

[2] A.C.V. Coelho, P. Souza Santos, Quim. Nova 30, 1 (2007) 146-152.

[3] M.M.T. Moreno, D. Bartolomeu, R.H. C. Lima, Cerâmica 55 (2009) 286-295.

[4] F.L. Formiga, J.C.S. Andrade, P.A.S. Araújo, D. A. Macedo, A. E. Martinelli, R. M. Nascimento, C.A. Paskocimas, Ceram. Ind. 18, 4 (2013) 30-36.

[5] S.C. Maestrelli, C.D. Roveri, A.G.P. Nunes, L.M. Faustino, G.F. Aielo, L.P.A. Pinto, C. Manochio, T.M.L. Cal, F. F. Ribeiro, N.A. Mariano, Cerâmica 59 (2013) 242-248.

[6] A.R.G. Azevedo, J. Alexandre, R.P. Oliveira, R.C. Souza, E.B. Zanelato, Anais $58^{\circ}$ Cong. Bras. Ceram., Bento Gonçalves, RS (2014) 47.

[7] A.S. Reis, V.P. Della-Sagrillo, J.N. Oliveira, F.R. Valenzuela-Diaz, Anais $58^{\circ}$ Cong. Bras. Ceram., Bento Gonçalves, RS (2014) 118.

[8] W.P. Gonçalves, V.J. Silva, J. Gomes, R.R. Menezes, G. A. Neves, H.C. Ferreira, L.N.L. Santana, Cerâmica 60 (2014) 316-322.
[9] I.D.S. Pereira, I.A. Silva, J.M. Cartaxo, R.R. Menezes, L.N.L. Santana, G.A. Neves, H.C. Ferreira, Cerâmica $\mathbf{6 0}$ (2014) 223-230.

[10] I.K. Oikonomopoulos, M. Perraki, N. Tougiannidis, T. Perraki, H.U. Kasper, M. Gurk, Appl. Clay Sci. 103 (2015) $1-9$.

[11] R.R. Menezes, P.M. Souto, L.N.L. Santana, G.A. Neves, R.H.G.A. Kiminami, H.C. Ferreira, Cerâmica 55 (2009) 163-169.

[12] I. A. Silva, J.M.R. Costa, R.R. Menezes, H.S. Ferreira, G.A. Neves, H.G. Ferreira, REM: Rev. Esc. Minas 66, 4 (2013) 485-491.

[13] S.Selmani, N. Essaidi, F. Gouny, S. Bouaziz, E. Joussein, A. Driss, A. Sdiri, S. Rossignol, J. Afr. Earth Sci. 103 (2015) 113-120.

[14] H.S. Santos, P. Kiyohara, A.C.V. Coelho, P.S. Santos, Cerâmica 52 (2006) 125-137.

[15] C.J. McConville, W.E. Lee, J. Am. Ceram. Soc. 88, 8 (2005) 2267-2276.

[16] W.E. Lee, G.P. Souza, C.J. McConville, T. Tarvornpanich, Y. Iqbal, J. Eur. Ceram. Soc. 28 (2008) $465-$ 471.

[17] H.M. Zhou, X.C. Qiao, J.G. Yu, Appl. Clay Sci. 80-81 (2013) 176-181.

(Rec. 17/04/2015, Ac. 30/05/2015) 